\title{
An open-source optimization tool for solar home systems: a case study in Namibia
}

\author{
Pietro Elia Campana $^{a^{*}, \text { Aksel Holmberg }^{a}, \text { Oscar Pettersson }^{a} \text {, Patrik Klintenberg }}{ }^{a}$, \\ Abraham Hangula ${ }^{b}$, Fabian Benavente Araoz ${ }^{c}$, Yang Zhang ${ }^{c}$, Bengt Stridh ${ }^{\text {a,d }}$, Jinyue \\ $\operatorname{Yan}^{\mathrm{a}, \mathrm{c}}$
}

${ }^{\mathrm{a}}$ School of Business, Society \& Engineering, Mälardalen University, Västerås 72123, Sweden

${ }^{\mathrm{b}}$ Namibia Energy Institute, Namibia University of Science and Technology, Windhoek 13388, Namibia

${ }^{\mathrm{c}}$ School of Chemical Science \& Engineering, KTH Royal Institute of Technology, Teknikringen 42, Stockholm 10044, Sweden

${ }^{\mathrm{d}} \mathrm{ABB}$ AB, Corporate Research, Västerås 72178, Sweden

\begin{abstract}
Solar home systems (SHSs) represent a viable technical solution for providing electricity to households and improving standard of living conditions in areas not reached by the national grid or local grids. For this reason, several rural electrification programmes in developing countries, including Namibia, have been relying on SHSs to electrify rural off-grid communities. However, the limited technical know-how of service providers, often resulting in over- or under-sized SHSs, is an issue that has to be solved to avoid dissatisfaction of SHSs' users. The solution presented here is to develop an open-source software that service providers can use to optimally design SHSs components based on the specific electricity requirements of the end-user.
\end{abstract}

The aim of this study is to develop and validate an optimization model written in MS ExcelVBA which calculates the optimal SHSs components capacities guaranteeing the minimum 
costs and the maximum system reliability. The results obtained with the developed tool showed good agreement with a commercial software and a computational code used in research activities. When applying the developed optimization tool to existing systems, the results identified that several components were incorrectly sized. The tool has thus the potentials of improving future SHSs installations, contributing to increasing satisfaction of end-users.

Keywords: Rural electrification; solar home system; optimization; open-source; Namibia.

\section{Introduction}

About 1.2 billion people, mainly distributed in Sub-Saharan Africa (SSA), Central, South and East Asia, and Latin America, have no access to the electric grid [1]. Electricity allows people to light their homes, start up businesses, pump water for drinking and irrigation purposes, and preserve food and medicines. Access to electricity is essential for improving living standards, facilitating the economic development, and, in few words, meeting the Millennium Development Goals set by the United Nations in 2000, in particular, eradicating poverty and hunger, and ensuring a sustainable development [2]. In 2006, the World Bank estimated that an investment of 860 billion US\$ was needed to achieve universal electricity access by 2030 , highlighting the difficulty of meeting this target [3]. In 2015, about 620 million people were still lacking access to electricity in SSA [4]. In 2013, only $32 \%$ of the population in Namibia (about 0.7 millions), the case study for this work, had access to electricity [5]. Most of the Namibian population with access to electricity lives in urban areas, whereas only $17 \%$ of the population living in rural areas has access to electricity [6]. Furthermore, it has been estimated that 74,000 households in peri-urban areas of Namibia have not yet been connected to the electricity grid, while 231,000 rural homes are without access to electricity [6]. Another issue is about the informal settlements since the government has the policy to not connect these areas to the electricity grid to prevent further urbanization. On the basis of the "Off-grid 
Energisation Master Plan”, those settlements are considered grey areas, which means that the master plans are unclear whether or how the access to electricity will be provided [7]. In Windhoek, the capital of Namibia, almost one third of the population (105,000 residents) was living in informal settlements in 2011 [8].

Many rural electrification programmes in developing countries have faced social, economic and political problems [9]. At the same time, the connection to the electricity grid requires high investment costs related to the infrastructure system and is typically very slow. The basic lighting needs in non-electrified rural areas are typically satisfied by using kerosene lamps, candles, flashlights and car batteries [1]. Power generation in off-grid areas relies often on diesel generators with several disadvantages, e.g. limited fuel supply, high maintenance and operation costs, and greenhouse gas emissions [10]. The use of fossil fuels, such as kerosene and liquid petroleum gas, and firewood constitutes the main energy source in rural areas. Therefore replacing fossil fuels with renewable energies can contribute to the sustainable development leading to improved health and living conditions and reaching climate change targets. To meet these targets, in 2004, the Namibian Ministry of Mines and Energy established the Namibian Renewable Energy Program in cooperation with funding from UN Development Program and the Global Environment Facility to enhance the electricity access and at the same time support the renewable energy sector [11]. The program aimed at spreading off-grid solar energy systems to fulfil the electricity requirements such as lighting, radio and television, water pumping for drinking and irrigation purposes, small electric tools and refrigeration. Part of the program was to finance small and medium enterprises to start businesses that would provide solar systems in rural areas. The loan limit for small and medium enterprises was set at 20,000-250,000 NA\$ (1 NA\$=0.067 US\$) while the loan limit for solar home systems (SHSs) and solar pumping systems was set at 20,000 NA $\$$ and 40,000 
NA\$, respectively [12]. The Namibian Ministry of Mines and Energy also developed a code of practice for the proper design and installation of SHSs [13].

SHSs are thus a technical solution for generating electricity for households not reached by the electricity grid or for areas too sparsely populated in order to build a local mini-grid. A SHS typically consists of four main components: the PV module, the charge controller, the battery, and the electrical loads. The PV module converts solar radiation into electricity that is stored into a battery, which buffers the mismatch between electricity production and consumption. The charge controller matches the current and voltage between PV module and the battery preventing over-charge and over-discharge. The loads are directly connected to the charge controller if they are direct current (DC) loads. In case of alternate current (AC) loads, an inverter is installed between the loads and the charge controller.

SHSs programmes have been used as a viable solution for starting rural electrification in developing countries all over the world with different success levels. With 2.6 million SHSs installations bringing electricity to $9 \%$ of the population, the Bangladesh SHSs programme is a successful example implemented through setting renewable energy targets, introducing incentives and promoting the autonomy of independent agencies [14]. On the other hand, the SHSs programme conducted in Papua Nuova Guinea is a typical example of unsuccessful programme, due to a mix of technical (low quality PV modules, limited availability of SHSs components, logistics, and lack of training), economic (poverty, lack of capitals, and limited financing), political (poor institutional capacities of the government), and social (high endusers expectations and frequent cases of vandalism resulting in low acceptance) barriers [15].

The field interviews conducted in this study in Namibia revealed that the investigated SHSs installations were not performed properly. The main problems included incorrect design and installation that result in unsatisfied end-users, which was also highlighted in a study conducted by Azimoh et al. in South Africa [16]. The wrong design and installation was 
mainly due to two different aspects: the first was related to an inaccurate load estimation that most of the time is bounded to the limited awareness of the end-users on their own actual electricity consumption; the second was related to the service providers which have limited knowledge of solar power systems and in general a limited technical know-how [17]. From the conducted survey and through personal communications with local energy specialists, the encountered problems are very likely to affect the majority of the SHSs installations [17]. A study in Tanzania showed how inefficient loads and ignoring load demand estimation are common mistakes that lead to SHSs failure [18]. Moreover, the lack of solar power systems knowledge as a factor for SHSs failures has been investigated in a previous study conducted by Azimoh et al. in South Africa [19]. The study showed that the use of non-optimal tilt angle for the PV modules had negative consequences on the system reliability, lifetime and consequently on the related economic aspects. The quality of SHSs installations in Namibia has been improved since the Solar Revolving Fund (SRF), a credit facility established by the Namibian Ministry of Mines and Energy to support renewable energies penetration in rural off-grid areas, was introduced to fund SHSs installations [17, 20]. Although the SRF has improved the quality of SHSs installations, many technical problems still remain, and further improvements can be done to support the utilization of SHSs in Namibia. For example, service providers have no access to advanced or commercial software tools during the design phase of SHSs which commonly results in rough size estimations without considering the Namibian code of practice. Hence, undersized PV modules or batteries will cause power shortages, undersized inverters or charge controllers will overheat and break, and undersized cables will cause high power transfer losses. Whereas, oversized SHSs components will result in unnecessary expenses for the usually poor households [17].

While most of the studies have been focused on optimization of power systems for rural areas, in particular hybrid power systems [21-23], few studies have focused on optimization of 
SHSs. Azimoh et al. studied the optimal SHSs tilt angle using the commercial software PVsyst ${ }^{\circledR}$ to maximize system reliability and lifetime, minimizing at the same time life cycle cost [19]. Kanyarusoke et al. presented an optimization model for finding the best SHSs components combination [24]. This optimization model is based on the SHSs daily simulations in TRNSYS ${ }^{\circledR}$ software and considers the following decisional variables: panel size, depth of discharge, charge efficiency, energy efficiency, battery capacity, number of batteries, and peak delivery current; and, the following two objective functions: minimizing panel size and utilizable storage capacity. The results of the optimization were also plotted on spatial maps of the entire Africa using Matlab® software. The spatial maps showed the spatial distribution of the SHSs components characteristics to minimize the battery storage capacity. A techno-economic assessment of SHSs with lithium-ion battery was conducted by Zubi et al. using the optimization software $\mathrm{iHOGA}{ }^{\circledR}[25]$. The study concluded that SHSs equipped with LED lights can have several economic, environmental and health advantages as compared to kerosene lamps.

In this study, we have developed an open-source MS Excel program written in visual basic (VBA) that optimizes the capacity of SHSs components. The developed model is a general model that can be applied everywhere in the world. The model is intended to help and support service providers to design optimal SHSs depending on the load profile construction and system components. The scope of developing this tool is to improve the function of SHS in Namibia and their reputation within the conducted electrification programmes. The program is based on an open-source genetic algorithm (GA) optimization model, called OptiCE, developed originally by Campana et al. [26, 27] for research activities on photovoltaic water pumping system for irrigation and successively used to other applications such as hybrid power systems for residential applications [28-30], and shrimp farms [31, 32]. 
Compared to the mentioned previous studies on SHSs, the novelty of this work lies in the following aspects: a) the optimizations routines are run at hourly time step to appreciate the mismatch between solar power production and load power requirements, and to study the SHSs components' performances; b) the optimizations includes all SHSs technical parameters, from tilt and azimuth angles orientation to cables size; c) the optimization has two objective functions that can guarantee the optimal SHSs capacity in terms of maximum reliability and minimum life cycle costs (LCC); d) to the best knowledge of the authors, there are no previous studies focusing on the development of a handy open-source program to support the optimal design of SHSs.

The current open-source version of the MS Excel-VBA program is going to be freely downloadable from the Website of Namibia University of Science and Technology and Namibia Ministry of Mines and Energy. It is already available from the OptiCE model website [27].

\section{Methodology}

This study has focused on the development of an open-source MS Excel-VBA tool to run optimization of SHSs. OptiCE [27], the simulation and optimization model at the basis of the MS Excel-VBA tool, is shortly described in the first part of this section; the second part of this section is mostly focused on the description of the MS Excel-VBA tool. In the last part of this section, the field survey and the validation of the developed open-source tool are described.

\subsection{OptiCE model}

OptiCE is an open-source model for optimization, simulation and design of hybrid power systems for off-grid and on-grid applications [27]. OptiCE models clean energy technologies integrated in microgrids or as distributed generation in larger grids. The model is written in Matlab® language and uses genetic algorithm (GA) to find the best power sources, storage 
system, and back-up source combination to minimize LCC and maximize power system reliability. In the case of SHSs simulation and optimization, only three sub-modules are used for the computations: solar radiation module, PV array module, and battery module. The power control units are modelled using an average static efficiency. The main input data are the climatic parameters for the specific location (global horizontal solar radiation, diffuse horizontal radiation, air temperature, and wind speed), and the electric load. The hourly simulation of the photovoltaic (PV) system is carried out through the following equation modified from Duffie and Beckman [33]:

$P_{P V}=\mathbf{n}_{P V, S T C}\left[1+\frac{\mu}{\eta_{P V, S T C}}\left(T_{a}-T_{S T C}\right)+\frac{\mu}{\eta_{P V, S T C}} \frac{9.5}{5.7+3.8 v} \frac{(N O C T-20)}{800\left(1-\eta_{P V, S T C}\right) G_{g, t}}\right] A_{P V} G_{g, t}$

where, $P_{P V}$ is the hourly power output from the PV system $(\mathrm{W}), \eta_{P V, S T C}$ is the efficiency of the PV module at standard test conditions (STC) $(\%), \mu$ is the temperature coefficient of the output power $\left(\% /{ }^{\circ} \mathrm{C}\right), T_{a}$ is the ambient temperature $\left({ }^{\circ} \mathrm{C}\right), T_{S T C}$ is the standard test conditions temperature $\left(25^{\circ} \mathrm{C}\right), v$ is the wind speed $(\mathrm{m} / \mathrm{s}), N O C T$ is the nominal operating cell temperature $\left({ }^{\circ} \mathrm{C}\right), A_{P V}$ is the $\mathrm{PV}$ array area $\left(\mathrm{m}^{2}\right)$ related to the array power peak, and $G_{g, t}$ is the global solar radiation on the tilted surface $\left(\mathrm{W} / \mathrm{m}^{2}\right) . G_{g, t}$ is calculated with the following equation [33]:

$G_{g, t}=G_{b_{r} t}+G_{d, t}+G_{r, t}$

where, $G_{b, t}\left(\mathrm{~W} / \mathrm{m}^{2}\right), G_{d, t}\left(\mathrm{~W} / \mathrm{m}^{2}\right)$, and $G_{r, t}\left(\mathrm{~W} / \mathrm{m}^{2}\right)$ are the beam, diffuse, and reflected components of the global solar radiation and are given by [33]:

$$
\begin{aligned}
& G_{b, t}=\frac{G_{g, h}-G_{d, h}}{\cos (90-\alpha)} \cos (\theta) \\
& G_{d, t}=G_{d, h} \frac{1+\cos (\beta)}{2}
\end{aligned}
$$


$G_{r, t}=\rho_{g} G_{d, h} \frac{1-\cos (\beta)}{2}$

where, $G_{g, h}$ is the global horizontal radiation $\left(\mathrm{W} / \mathrm{m}^{2}\right), G_{d, h}$ is the diffuse horizontal radiation $\left(\mathrm{W} / \mathrm{m}^{2}\right), \alpha$ is the solar altitude $\left(^{\circ}\right), \theta$ is the angle of incidence $\left(^{\circ}\right)$, and $\rho_{g}$ is the ground reflectance. The angle of incidence $\theta$ depends on the declination angle $\delta\left({ }^{\circ}\right)$, latitude $\varphi\left({ }^{\circ}\right)$, tilt angle $\beta\left({ }^{\circ}\right)$, azimuth angle $\gamma\left({ }^{\circ}\right)$ and hour angle $\omega\left(^{\circ}\right)$. The battery model calculates the state of charge of the battery $S O C_{b a t}$ according to the following two equations for charging and discharging respectively [34]:

$$
\begin{aligned}
& S O G_{\text {bat }}(t)=S O C_{\text {bat }}(t-1)\left(1-\sigma_{s d}(t)\right)+\left[P_{P V}(t)-\frac{P_{\text {load }}(t)}{\eta_{\text {inv }}}\right] \eta_{c}(\text { Charging }) \\
& S O C_{b a t}(t)=S O C_{\text {bat }}(t-1)\left(1-\sigma_{s d}(t)\right)+\left[\frac{P_{\text {load }}(t)}{\eta_{\text {inv }}}-P_{P V}(t)\right](\text { discharging })
\end{aligned}
$$

where, $t$ indicates the time step at which the parameter is calculated (hours), $\sigma_{s d}$ is the hourly self-discharge rate, $P_{\text {load }}$ is the load power consumption $(\mathrm{W}), \eta_{\text {inv }}$ is the inverter efficiency (\%), and $\eta_{c}$ is the charge efficiency of the battery bank (\%) [34]. The optimization model maximizes the system reliability REL (\%) and at the same time minimize the LCC (NA\$). The LCC takes into consideration investment costs, tax deduction due to investment depreciation, annual maintenance and operation costs, replacement costs, and salvage value. REL and LCC are thus given by the following relationships [35]:

$R E L=\frac{H_{S L}}{8760} 100$

$L C C=I C C-\sum_{n=1}^{N} \frac{d_{t}}{(1+i)^{n}} t r+\sum_{n=\mathbf{1}}^{N} \frac{a_{t}}{(1+i)^{n}}(1-t r)+\sum_{r=\mathbf{1}}^{R} \frac{I C C_{c}}{(1+i)^{r l_{c}}}(1-t r)-\frac{s}{(1+i)^{N}}(t r)$

where, $H_{S L}$ is the number of hours the SHS can meet the load during the year (hours) (the reliability concept is the opposite of the loss of load probability (LOLP) concept), ICC is the initial capital cost of the system (NA $\$$ ), $N$ is the lifetime of the project (years), $n$ refers to the 
$\mathrm{n}$-th year of the project (year), $d_{t}$ is the annual depreciation (NA $\left.\$\right), i$ is the interest rate $(\%), t r$ is the tax rate $(\%), a_{t}$ is the annual maintenance and operation costs (NA $\$$ ), $r$ refers to the $r$-th replacement with $R$ total number of replacements during the lifetime of the project, $I C C_{c}$ is the investment cost of the c-th component to be replaced (NA $\$$ ), $l_{c}$ is the lifetime of the c-th component to be replaced (years), and $s$ is the salvage value (NA $\$$ ). $I C C_{c}$ and $l_{c}$ are vectors of c-th component corresponding to the system components that require replacements during the system lifetime. The total number of replacements $R$ is a function of the lifetime of the components to be replaced and is given by the following equation:

$$
R=\text { floor }\left(\frac{N}{l_{c}}\right)-1
$$

Where, floor is the Matlab ${ }^{\circledR}$ function that rounds a number to the next smaller integer. Taking into account the salvage value, Equations 10 avoids to carry out the last replacement in correspondence of the end life of the project. The levelized cost of electricity (LCOE) $(\mathrm{NA} \$ / \mathrm{kWh})$ is then calculated from the LCC considering the potential energy production during the lifetime of the project, and it is given by [35]:

$$
L C O E=\frac{L C C}{E P \Sigma_{n=1}^{N} \frac{y_{t}}{(1+i)^{n}}}
$$

where, $y_{t}$ is the annual energy production degradation rate $(\%)$. The optimization is conducted using genetic algorithms (GA) as optimization technique in Matlab ${ }^{\circledR}$ Global Optimization Toolbox. The decision variables include the PV array power, the tilt angle $\beta\left({ }^{\circ}\right)$, the azimuth angle $\gamma\left({ }^{\circ}\right)$, and the battery capacity $(\mathrm{kWh})$.

\subsection{MS Excel-VBA program}

\subsubsection{Optimization}

The developed MS Excel-VB program is based on OptiCE model. Nevertheless, differently from OptiCE model, the MS Excel-VB program presented in this study is performing optimizations through an iterative method developed in VBA and described 
afterwards. Including GA could have been possible through the use of add-in programs for MS excel, as for instance Solve XL [36] used in Campana et al. [26]. Nevertheless, in this study we did not consider such option because including GA add-in programs for MS excel leads to extra costs for the SHSs' providers. Thus, the implementation of powerful GA add-in for MS Excel goes beyond the main scope of this study of developing a handy and affordable tool.

Assuming a specific load, the optimization model finds the optimal SHSs components size by maximizing the system reliability and minimizing LCC. The optimal SHSs components combination is achieved through several iterations evaluating all the possible components combinations that satisfy the objectives and end-user choices. Every iteration, the solar radiation on the PV array and the SHSs components performances are calculated with a time step of one hour. A schematic diagram of how the optimization macro works is given in Fig. 1. 


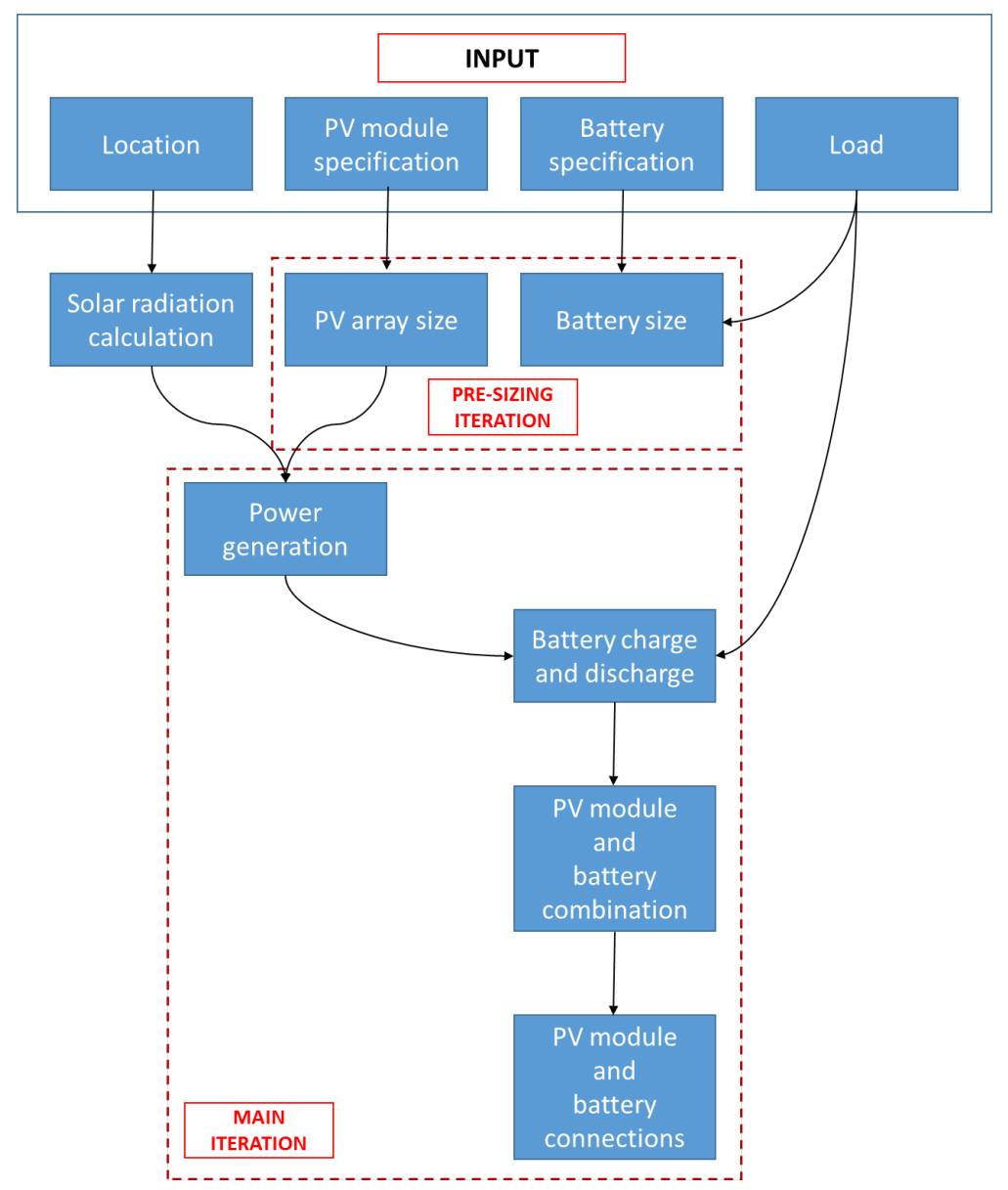

Fig. 1: Optimization procedure flowchart.

The macro reads the main user input data (location and related hourly climatic values, load, and PV modules and battery details). The load profile refers to the appliances used during the day, their rated power consumption, the corresponding time, and duration of use. The load profiles used in this work refers to the data gathered from quotations made by service providers for their clients. The hourly load profile has been created from a standard hourly load profile taken from a previous study conducted in Algeria [34]. The standard hourly load profile is marked out by load peaks during morning, lunch and a major peak during the evening. Two additional load profiles were created, to represent day time businesses and night time businesses. A summary of the standard load profiles is depicted in Fig. 2. 


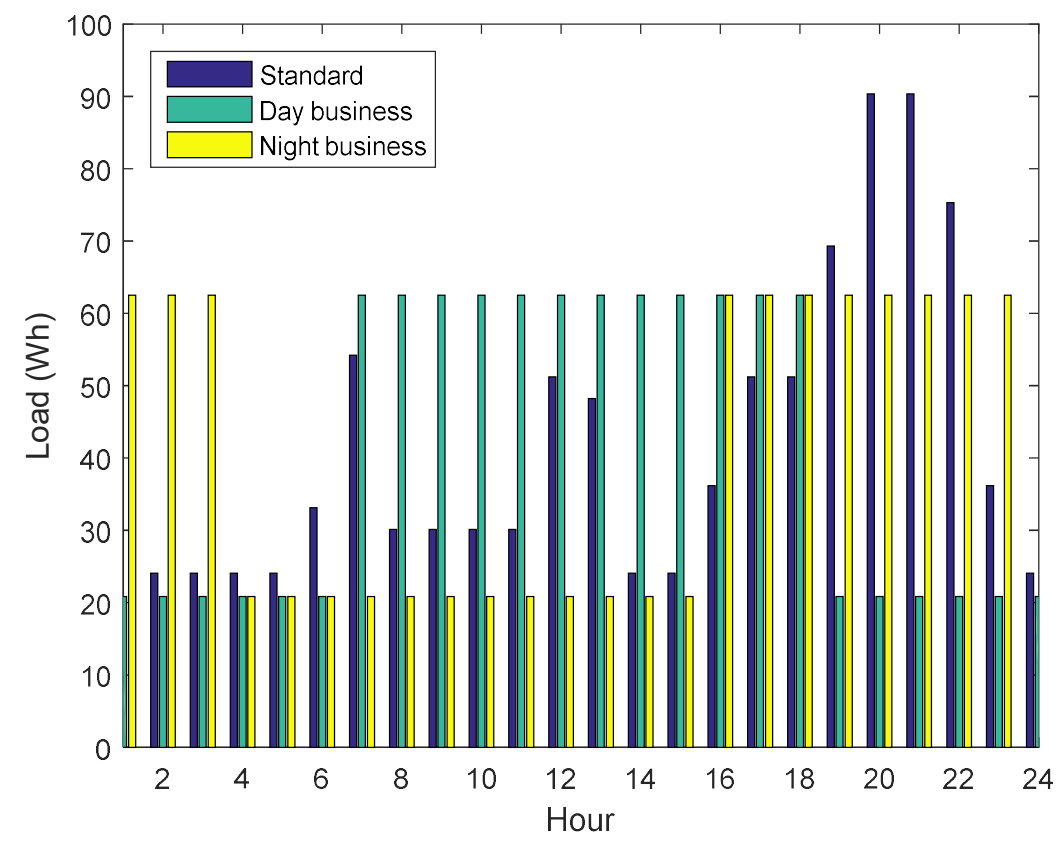

Fig. 2: Standard load profiles.

The starting point for the optimization process is to provide a pre-size estimation of the SHSs components. The pre-sizing of the PV array power peak $P_{p v}\left(\mathrm{~kW}_{\mathrm{p}}\right)$ and battery capacity $C_{b a t}$ (Ah) is conducted using the following equations [37]:

$$
\begin{aligned}
& P_{\text {pv }}=\frac{1}{\eta_{c} \eta_{\text {df }} \eta_{c c} \eta_{\text {inv }}} \frac{E_{\text {load }}}{P_{\text {solar }}} \\
& C_{\text {bat }}=\frac{E_{\text {load }}}{U_{b}} \frac{d}{C C_{\text {limit }}}
\end{aligned}
$$

Where, $\eta_{c}$ is the charge efficiency of battery bank (75\%), $\eta_{d f}$ is the de-rating factor taking into consideration several losses such as those due to temperature, mismatching, wiring, shading, and soiling (90\%), $\eta_{c c}$ is the charge controller efficiency $(95 \%), \eta_{i n v}$ is the inverter efficiency $(90 \%), E_{\text {load }}$ is the daily load $(\mathrm{kWh}), P_{\text {solar }}$ is the peak sun hours (hour), $U_{b}$ is the battery bus voltage (V), $d$ is the days of autonomy (days), and $C C_{\text {limit }}$ is the limit of the state of charge (\%). The efficiencies used in this work are taken from previous studies conducted on off-grid solar systems $[34,37,40] . E_{\text {load }}$ and $P_{\text {solar }}$ corresponds to the daily load and peak sun hours for the worst month marked out by the highest ratio between $E_{\text {load }}$ and $P_{\text {solar }}$. The $C C_{\text {limit }}$ has been 
set at $50 \%$ according to the Namibian code of practice for the used lead batteries [13]. The pre-sizing helps to reduce the simulation time and should not be considered as the final optimal result since it might deviate greatly from the optimal one.

Through iterations, the VBA macro tries several combinations of PV array and battery capacity until the components combination reaches the fixed reliability limit by performing hourly simulations. Once the reliability threshold is reached, the macro selects the combination with the lowest LCC. The specific LCC of the system is calculated using Equation 9 and given as input to the MS Excel-VBA program. When the optimization is complete, the calculated optimal PV and battery capacities are rounded up to match the PV modules and battery specifications chosen by the end-user in the MS Excel-VBA program drop-down menus.

In the next step, the optimal wiring between PV modules and battery bank is calculated considering the charge controller open circuit voltage limit $V_{o c}(\mathrm{~V})$ and maximum current $C_{\max }$ (A) given by the specification of the chosen charge controller in the MS Excel-VBA program drop-down menu. The macro evaluates all the possible PV modules series and parallel combinations within the system constraints. The maximum voltage limit of the charge controller has to be above the maximum open circuit voltage of the PV array. Similarly, the optimal combination of the batteries is conducted considering the system voltage chosen by the end-user in the MS Excel-VBA program drop-down menu.

After optimizing the $\mathrm{PV}$ and battery connections, the cable size $A\left(\mathrm{~mm}^{2}\right)$ is calculated assuming $1 \%$ the maximum acceptable power loss at maximum power $\mathrm{P}_{\text {loss }(\%)}(\%)$ [13] according to the following equation:

$$
A=\frac{2 I_{\max L \rho}^{2}}{P_{\operatorname{loss}(\%)} P_{\max m}}
$$


Where, $I_{\max }$ is the maximum current $(\mathrm{A}), L$ is the cable length $(\mathrm{m}), \rho$ is the resistivity $(\Omega \cdot \mathrm{m})$, and $P_{\max }$ is the transferred maximum power along the cables (W). The cross sectional area of the cables has been calculated taking into consideration the power losses that are function of the current flowing through the cable, cable length, and resistivity of the material. $P_{\text {loss(\%) }}$ is given by the ratio between the power losses in the cables and the transferred maximum power. The cable size is rounded up to a cable size commonly available on the market.

The inverter rated power $P_{i n v}(\mathrm{~W})$ is calculated with the following equation:

$P_{\text {inv }}=\frac{{ }_{2} P_{\text {load,max }}}{\eta_{\text {inv }}}$

Where, $P_{\text {load,max }}$ is the maximum load of the household set $100 \%$ higher for safety reasons due to surge currents [13].

\subsubsection{MS Excel-VBA program overview}

The model consists of three main sheets: "Instructions", "Input-Output", and "Quotation". The first one provides an overview of how the model works and which are the main input data to be defined; the second sheet represents the core of the program where input data are entered, and results and warnings are displayed. The last sheet provides a detailed SHS quotation. All worksheets containing the calculations are hidden and locked. An image of the "Input-Output" sheet, is depicted in Fig. 3.

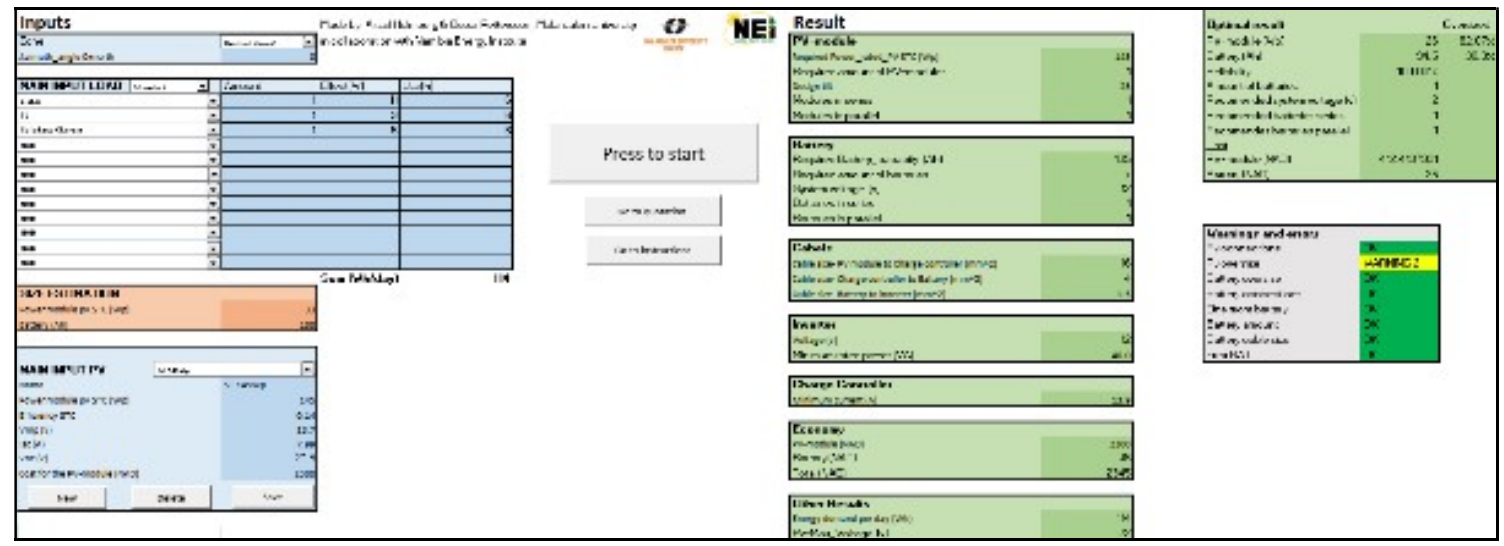

Fig. 3: Screenshot of the "Input-Output" sheet of the MS Excel-VBA program. 
The main inputs required by the model are: Namibia zone where the SHS is going to be installed (this is related to the solar radiation pattern for a typical city within the zone), azimuth angle, the electric load, specifications of the PV-module, battery, and charge controller. According to the Namibian code of practice, the entire national territory is divided into three zones, as shown in Fig. 4. Each zone has a recommended tilt angle: from zone 1 to 3 , the recommended tilt angle is $25^{\circ}, 30^{\circ}$, and $35^{\circ}$ respectively [13].

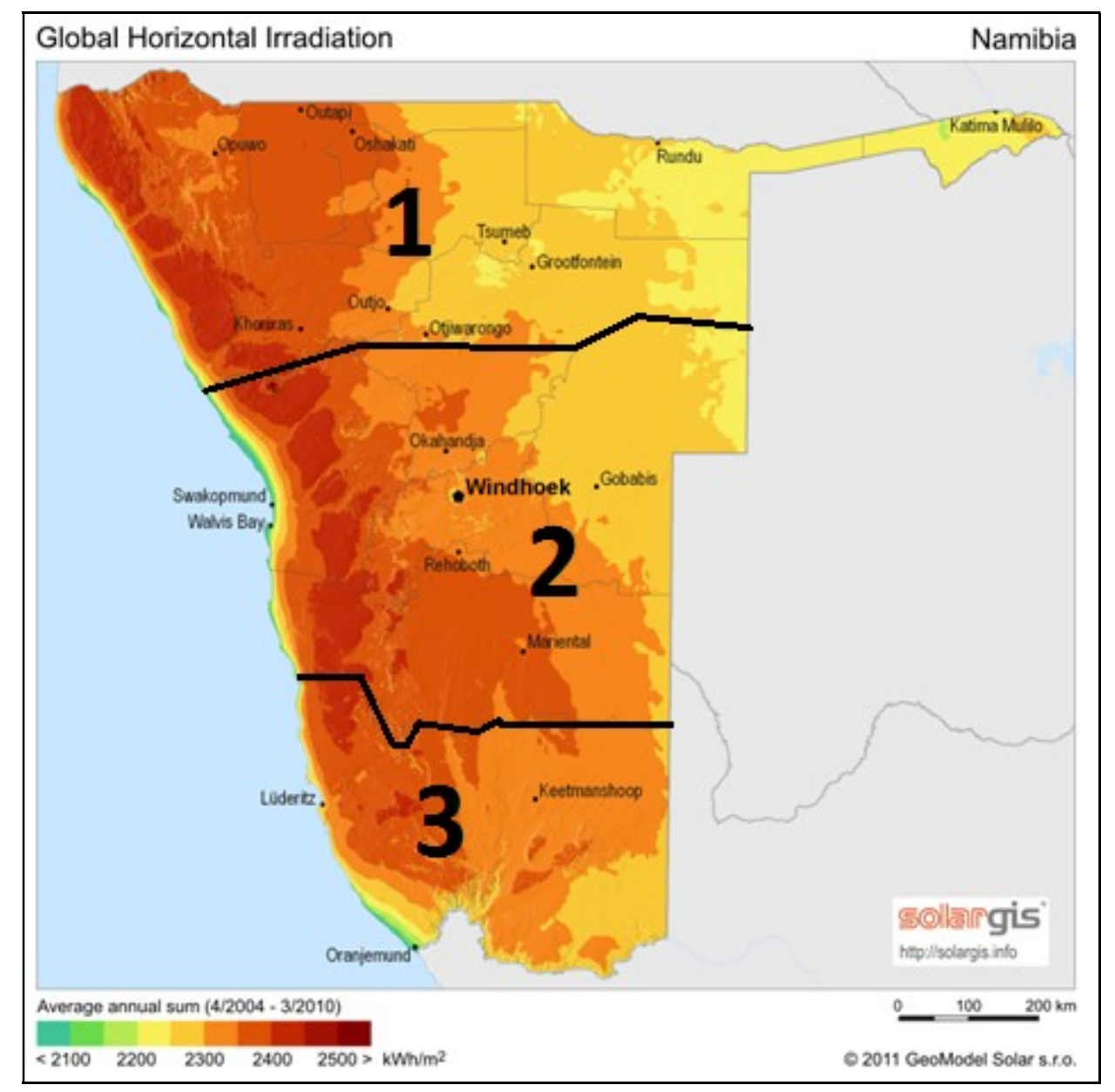

Fig. 4: Division zones for Namibia and related global horizontal irradiation distribution [38].

For instance, the selection block of the PV modules and relative PV modules specifications is depicted in Fig. 5. 


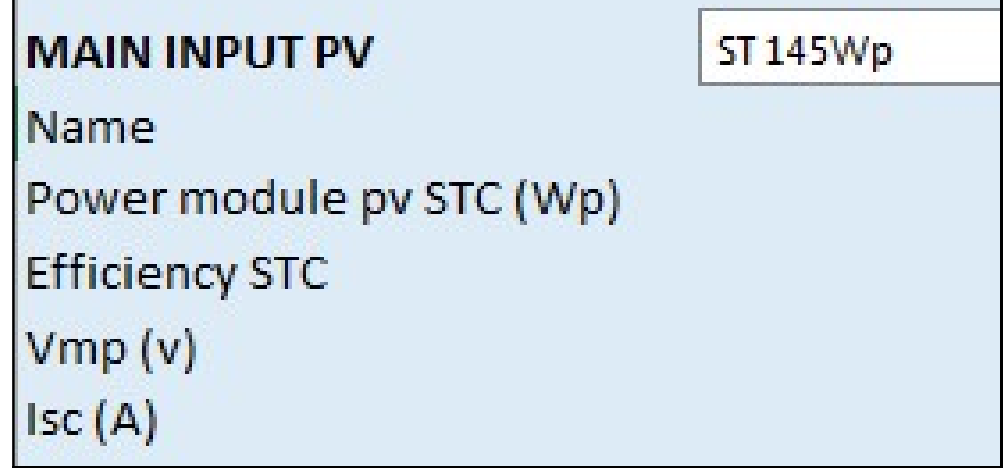

Fig. 5: Screenshot of the PV module selection block in the "Input-Output" sheet of the MS Excel-VBA program

Under results, the optimal size of the PV array and battery, and the optimal electric wiring are shown. Moreover, various parameters that are not required for the installation itself but still important output, such as the estimated battery life span, system reliability, and average daily depth of discharge (DOD) are also shown. The MS Excel-VBA program also presents the "Warnings and errors" of the optimization. "Warnings" are divided into 5 categories: PV connections, PV array capacity, battery connections, battery capacity, and system voltage. The section "Errors" mainly include the number of batteries, cable sizing, and solution not achieved.

All the climatic parameters used in this study have been taken from the global climatic database Meteonorm [41].

\subsection{Validation through field study}

To test and validate the model, field studies were conducted. A field study was conducted at a small bar situated in an informal settlement in Katutura, Windhoek, shown in Fig. 6. 


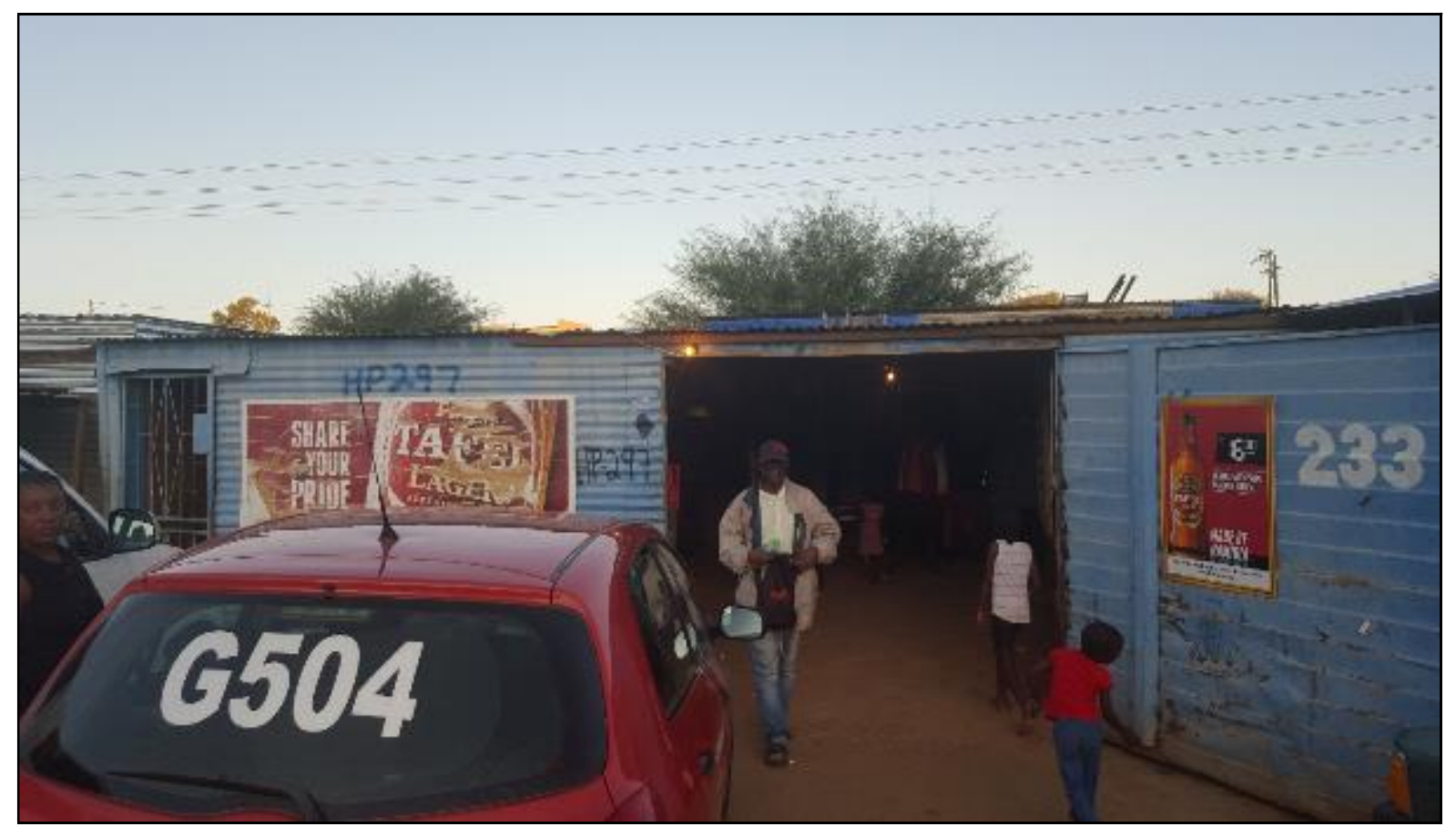

Fig. 6: Bar in an informal settlement in Katutura, Windhoek.

The bar owners were interested in buying and installing a SHS to avoid the current illegal power purchase from a nearby grid connected household, at a cost of around 125 NA $\$$ per day. Part of the field study was also used to investigate the electricity consumption of the bar and provide suggestions for efficiency improvements. The overall electricity consumption was $28 \mathrm{kWh} /$ day, corresponding to an illegal electricity price of $4.5 \mathrm{NA} \$ / \mathrm{kWh}$. Most of the electricity was consumed by poor quality fridges used to cool beverages. The results from the measurement campaign showed that the fridges electricity consumption was around 20 $\mathrm{kWh} /$ day. Modern energy efficient fridges would reduce the fridges electricity requirements from 19.2 to $2.7 \mathrm{kWh} /$ day. The data gathered during the field study was entered into the MS Excel-VBA program to design the optimal SHS for the bar. The main assumptions of the related economic analysis are summarized in Table 1 . The costs are based on a quotation of a similar SHS installed in the same area, which was gathered during the field study. The investment on new high efficiency fridges has not been taken into consideration in this work. 
Table 1: Economic assumptions (based on a real solar home system quotation gathered during the field study).

\begin{tabular}{|l|c|}
\hline Parameter & Value \\
\hline PV module cost per unit $\left(\mathrm{NA} \$ / \mathrm{W}_{\mathrm{p}}\right.$ ) & 13.5 \\
\hline Battery cost per unit $(\mathrm{NA} \$ / \mathrm{Wh})$ & 1.2 \\
\hline Interest rate (\%) & 10 \\
\hline Engineering and installation costs (\% ICC) & 5000 \\
\hline Cost for transport and accessories (NA\$) & 5 \\
\hline Annual operation and maintenance cost (\% ICC) & 15 \\
\hline Tax rate (\%) & $25[34]$ \\
\hline Lifetime of the project (years) & $4[34]$ \\
\hline Battery lifetime (years) & $10[34]$ \\
\hline Inverter lifetime (years) & -0.3 \\
\hline PV module ageing factor (\%/year) & \\
\hline
\end{tabular}

Beside the bar case study, the results from the MS Excel-VBA program were compared to three previously installed SHSs. The load estimations used by the service providers to design the three SHSs were taken as input data for the MS Excel-VBA program for the comparison. A summary of the gathered data for the three installed SHSs is given in Table 2 for Households 1, 2 and 3 (H1, H2, and H3). The PV module of the SHS installed on the roof of $\mathrm{H} 2$ is presented in Fig. 7, while the other SHS components (charge controller, battery, inverter, and junction boxes) are presented in Fig. 8 .

Table 2: Details of the investigated solar home systems.

\begin{tabular}{|l|c|c|c|}
\hline Parameter & H1 & H2 & H3 \\
\hline Equipment & $\begin{array}{c}2 \text { lights, TV, cell phone } \\
\text { charger, fridge }\end{array}$ & $\begin{array}{c}\text { 4 lights, TV, radio, hi-fi, } \\
\text { freezer }\end{array}$ & $\begin{array}{c}\text { 3 lights, TV, radio, hi-fi, } \\
\text { freezer, hair clipper }\end{array}$ \\
\hline Use (hours/day) & $4-8$ & $4-6$ & 2 \\
\hline Estimated load (Wh/day) & 1700 & 1800 & 500 \\
\hline System voltage (V) & 12 & 12 & 12 \\
\hline PV array characteristics & $\begin{array}{c}\text { PV modules } 145 \mathrm{~W}_{\mathrm{p}}, \\
14 \% \text { efficiency }\end{array}$ & $\begin{array}{c}2 \mathrm{PV} \text { modules } 200 \mathrm{~W}_{\mathrm{p}}, \\
15 \% \text { efficiency }\end{array}$ & $\begin{array}{c}1 \text { PV module } 50 \mathrm{~W}_{\mathrm{p}}, \\
11.5 \% \text { efficiency }\end{array}$ \\
\hline Battery characteristics & 5 Willard $105 \mathrm{Ah}, 12 \mathrm{~V}$ & 6 Raylite $96 \mathrm{Ah}, 12 \mathrm{~V}$ & 1 Raylite $96 \mathrm{Ah}, 12 \mathrm{~V}$ \\
\hline Inverter $(\mathrm{VA})$ & 800 & 2400 & 350 \\
\hline PV module cost per unit $\left(\mathrm{NA} \$ / \mathrm{W}_{\mathrm{p}}\right)$ & 15.9 & 18.0 & 31 \\
\hline Battery cost per unit $(\mathrm{NA} \$ / \mathrm{Ah})$ & 13.8 & 13.0 & 13.0 \\
\hline
\end{tabular}




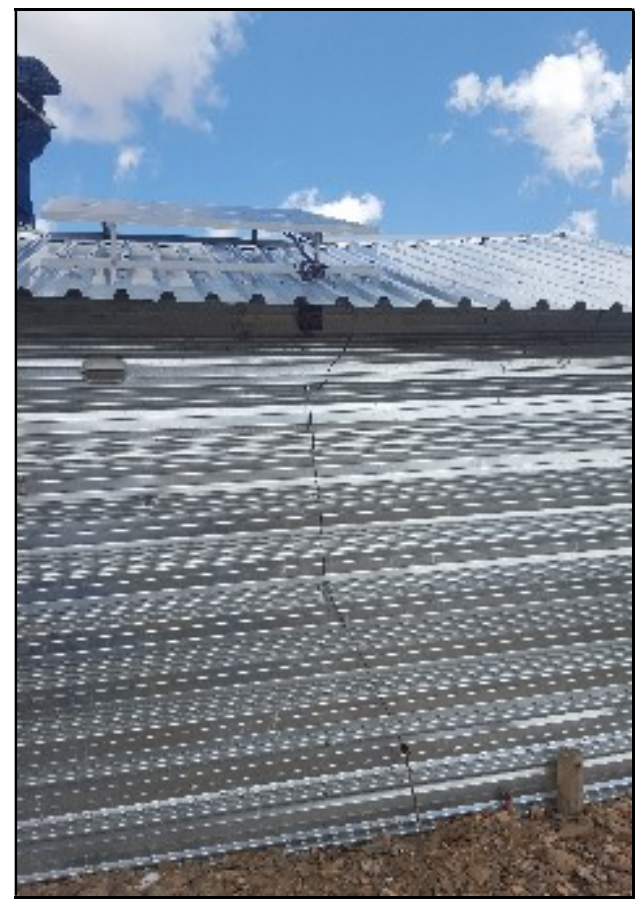

Fig. 7: PV module of the solar home system installed on the roof of one of the investigated households (Household 2).

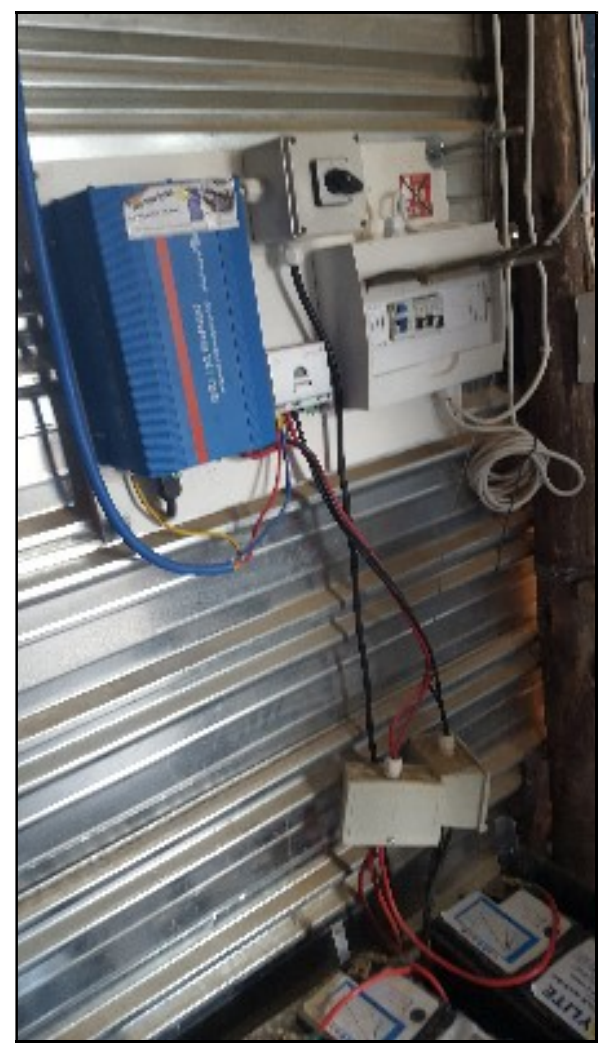

Fig. 8: Details of the solar home system installation at one of the investigated households (Household 2) 
Using the same input data gathered during the field study, the result obtained from the commercial software PVsyst ${ }^{\circledR}$ and the open-source code OptiCE [25] were used to compare and validate the results achieved by the MS Excel-VBA program.

\section{Results}

In this section, the main findings regarding SHSs optimization and MS Excel-VBA program validation are presented. The results concerning the system optimization are divided into two main parts: the first focuses on the optimization of the SHS for the inspected bar and related economic aspects; and, the second focuses on the comparison between the three previously installed SHSs and the optimal results achieved with the developed MS Excel-VBA program.

\subsection{Solar home systems optimization}

\subsubsection{Bar case study}

The configuration of the optimized SHS computed by the MS Excel-VBA program for the investigated bar is presented in Table 3. The optimization results have been obtained assuming that the current fridges are exchanged for modern energy efficient ones with an average daily consumption of $11 \mathrm{kWh}$. One day of autonomy and $99.9 \%$ reliability have been considered as setting parameters.

Table 3: Optimization results of the investigated solar home system for a bar in an informal settlement in Katutura, Windhoek.

\begin{tabular}{|l|c|}
\hline Parameter & Results \\
\hline Tilt of the PV array $\left({ }^{\circ}\right)$ & $25($ Zone 2$)$ \\
\hline Peak power of the PV array $\left(\mathrm{W}_{\mathrm{p}}\right)$ & 2940 \\
\hline System voltage $(\mathrm{V})$ & 24 \\
\hline Battery capacity $(\mathrm{Ah})$ & 16 \\
\hline Cable size - PV module to Charge controller $\left(\mathrm{mm}^{2}\right)$ & 16 \\
\hline Cable size - Charge controller to Battery $\left(\mathrm{mm}^{2}\right)$ & 4 \\
\hline Cable size - Battery to inverter $\left(\mathrm{mm}^{2}\right)$ & 2118 \\
\hline Inverter capacity $(\mathrm{VA})$ & 7027 \\
\hline Total annual power generation $(\mathrm{KWh})$ & 99.9 \\
\hline Reliability of the system $(\%)$ & (14 batteries AGM $25 \mathrm{~V})$ \\
\hline
\end{tabular}


It is of great interest to analyse the economic aspects of the investigated system, considering the high price of the illegally purchased electricity. The economic analysis showed that a payback period of around nine years (9.3 years) can be achieved when comparing the SHS with the scenario of purchasing electricity illegally $(4.5 \mathrm{NA} \$ / \mathrm{kWh})$. The resulting SHS LCOE is $3.3 \mathrm{NA} \$ / \mathrm{kWh}$ which is higher compared to the current electricity price for grid connected households, $2 \mathrm{NA} \$ / \mathrm{kWh}$ [39], but far low compared to the electricity price from an illegal connection. It has to be noted that that the price of illegally purchased electricity can be higher than the value considered in this study, increasing the profitability of installing SHSs.

\subsubsection{Installed solar home systems}

The comparison between the previously installed SHSs and the resulting optimization of these systems using the developed tool is summarized in Table 4, where the most important differences are highlighted in bold characters.

Table 4: Comparison between installed solar home system (iSHS) and optimized solar home system (oSHS) with the developed MS Excel-VBA program (the most important differences are highlighted in bold characters).

\begin{tabular}{|c|c|c|c|c|c|c|}
\hline Parameter & $\begin{array}{c}\text { iSHS } \\
\text { H1 }\end{array}$ & $\begin{array}{c}\text { oSHS } \\
\text { H1 }\end{array}$ & $\begin{array}{c}\text { iSHS } \\
\text { H2 }\end{array}$ & $\begin{array}{c}\text { oSHS } \\
\text { H2 }\end{array}$ & $\begin{array}{c}\text { iSHS } \\
\text { H3 }\end{array}$ & $\begin{array}{c}\text { oSHS } \\
\text { H3 }\end{array}$ \\
\hline Tilt of the PV array $\left(^{\circ}\right)$ & 15 & 25 & 26 & 25 & 25 & 25 \\
\hline Peak power of the PV array $\left(\mathrm{W}_{\mathrm{p}}\right)$ & 435 & 446 & 400 & 468 & 50 & 88 \\
\hline Battery capacity $(\mathrm{Ah})$ & 525 & 530 & $576(12 \mathrm{~V})$ & $277(24 \mathrm{~V})$ & 96 & 77 \\
\hline Cable size- PV module to Charge controller $\left(\mathrm{mm}^{2}\right)$ & 4 & 4 & 6 & 4 & 4 & 2.5 \\
\hline Cable size- Charge controller to Battery $\left(\mathrm{mm}^{2}\right)$ & 4 & 16 & 10 & 4 & 0.5 & 2.5 \\
\hline Cable size- Battery to inverter $\left(\mathrm{mm}^{2}\right)$ & 16 & 10 & 6 & 2,5 & 1 & 6 \\
\hline Inverter capacity (VA) & 1200 & 600 & 2400 & 684 & 350 & 440 \\
\hline Reliability of the system & $99.7 \%$ & $99.9 \%$ & $99.6 \%$ & $99.9 \%$ & $45.5 \%$ & $99.9 \%$ \\
\hline
\end{tabular}

The SHS for H1 was correctly designed, in particular the PV and battery capacities. The impact of the tilt angle on the system reliability has no significant impact on the inspected system for $\mathrm{H} 1,99.7 \%$ versus $99.9 \%$. The size of the cable connecting the charge controller and the battery was undersized producing power transfer losses of about $4 \%$. The optimal results for $\mathrm{H} 2$ shows that the installed PV system was undersized while the battery capacity 
was correctly sized. For both $\mathrm{H} 1$ and $\mathrm{H} 2$ the inverter was considerably oversized. The cable size of $\mathrm{H} 2$ could be significantly reduced by adopting a $24 \mathrm{~V}$ system. H3 shows that the battery is correctly sized while the PV array is undersized requiring an additional PV module, which would significantly improve the system reliability. Moreover, the inverter capacity was undersized compared to the likely high current drawn.

From the survey and through interviews with key informants, it was revealed that the reason for under- and oversized SHSs is not only due to the knowledge and technical skills of the service providers, but also an intrinsic economic reason behind the incorrect sizing of the systems. The maximum loan provided by SRF for SHS is 35,000 NA\$. When the client receives the loan from SRF, the service providers are limited to offer a system that does not exceed a cost of 35,000 NA\$, independently from the client's electricity needs. Most of the time this results in undersized systems. In the case when a larger loan can be taken from the bank, the design provided by the service providers often results in oversized systems. To protect the customers from service providers delivering incorrectly sized systems, SRF has created a "blacklist" of service providers.

The load assessment represents a key issue in designing off-grid system, and in particular for SHSs since most of the time a back-up power (diesel generator or electric grid) is not available. The impact of the load profile on the optimal PV system and battery capacity is depicted in Fig. 9. The sensitivity analysis refers to H1 for a $24 \mathrm{~V}$ battery system. Shifting most of the load to daytime helps to decrease both the PV and battery size due to the lower mismatch between supply and demand. On the other hand, shifting most of the load to night time increase the SHSs capacity, in particular the PV capacity.

It is also of interest to investigate the impact of the SHSs tilt angle on the energy production and on the system reliability as depicted in Fig. 10, and on the PV and battery optimal capacities as depicted in Fig. 11. The sensitivity analyses refer to both $\mathrm{H} 1$ and $\mathrm{H} 2$ and were 
ran only with OptiCE. The results achieved with the developed MS Excel-VBA program are also superimposed. It has to be noted that, as aforementioned in section 2.2.2, the user of the developed MS Excel-VBA program can only choose three tilt angles $\left(25^{\circ}, 30^{\circ}\right.$ and $\left.35^{\circ}\right)$ depending on the Namibian zone as specified from the Namibian code of practice for solar energy projects [13]. The comparison with PVsyst ${ }^{\circledR}$ in terms of optimization results difficult because the software performs optimization through a completely different approach compared to OptiCE or the developed MS Excel-VBA program. In PVsyst ${ }^{\circledR}$ software the user defines first the battery capacity depending on the days of autonomy. Afterwards, the PV capacity is optimized to reach the desired reliability. Unlike PVsyst ${ }^{\circledR}$, the developed MS Excel-VBA program, as well as OptiCE, carries out a complete optimization considering the combination of both PV capacity and battery capacity at the same time. Taking into consideration the annual energy production, the optimal tilt angle is $25^{\circ}$ at the study site. Nevertheless, the optimal tilt angle as a function of the system reliability is $15^{\circ}$. This mismatch is due to the climatic patterns of Namibia, where the summer season corresponds also with the rain season in most of the country. Thus, a lower tilt angle is required to generate more electricity during summer penalizing the annual electricity generation. Those results are also reflected on the relationship between optimal tilt angles and PV capacities. The lowest PV capacities are achieved with a tilt angle of $15^{\circ}$ due to the higher solar irradiation harvested. The tilt angle significantly affects the optimal PV array size, while its effect on the battery capacity is less significant. 


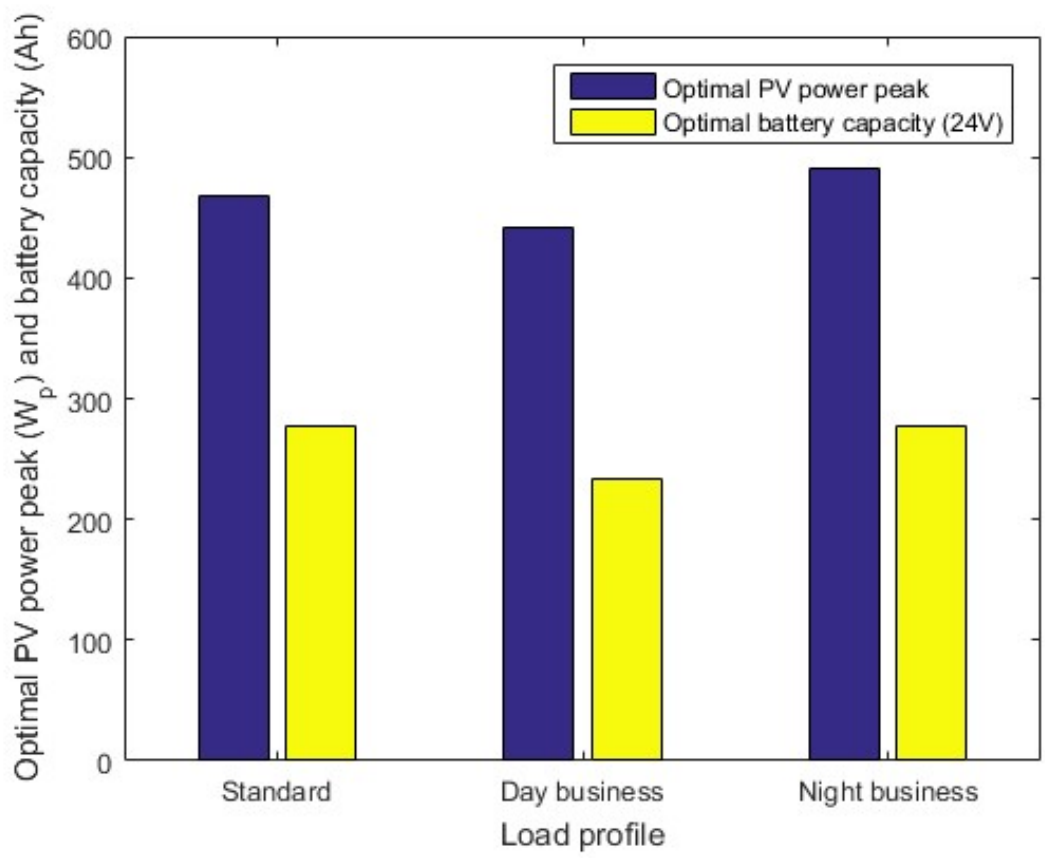

Fig. 9: Impact of the load profile on the optimal PV power peak and battery capacity for Household 1.
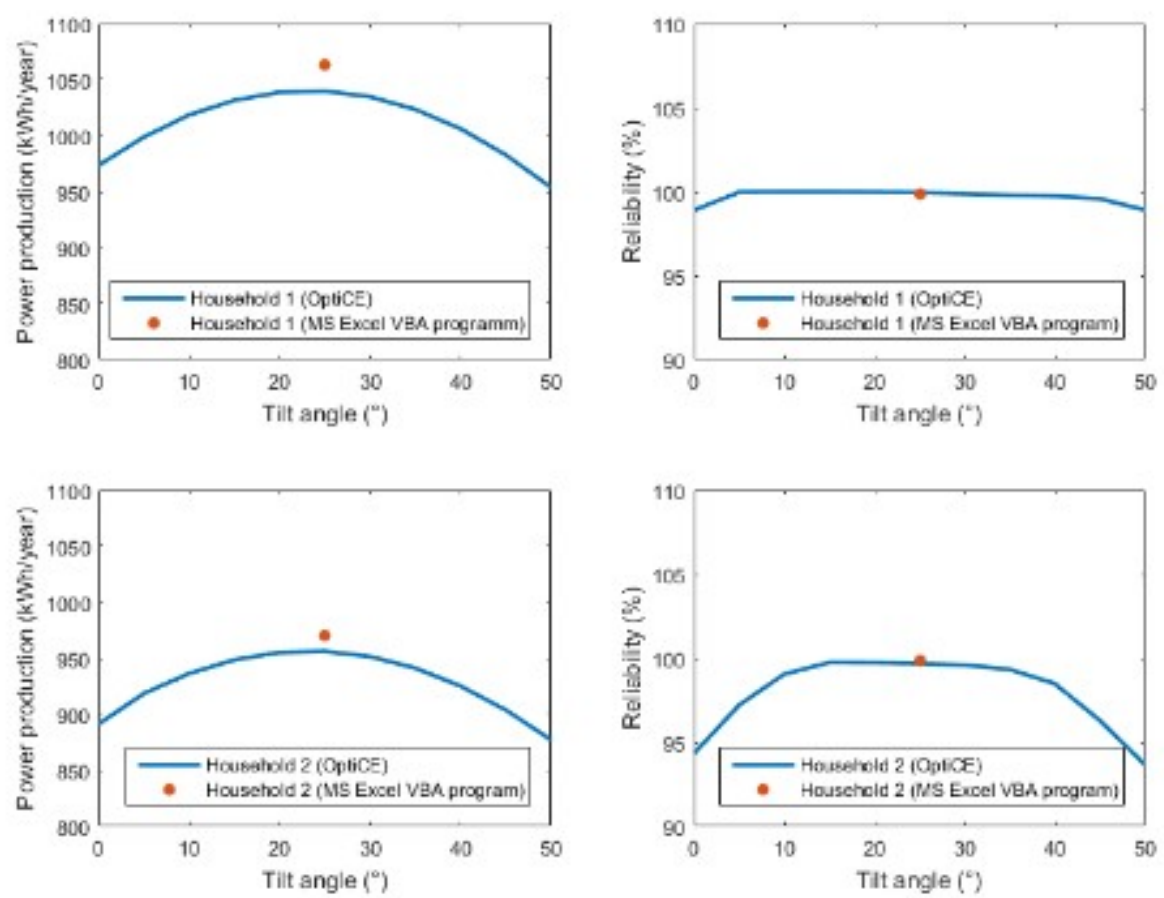

Fig. 10: Impact of the tilt angle on the annual power production (left) and system reliability (right) for Households 1 and 2. 

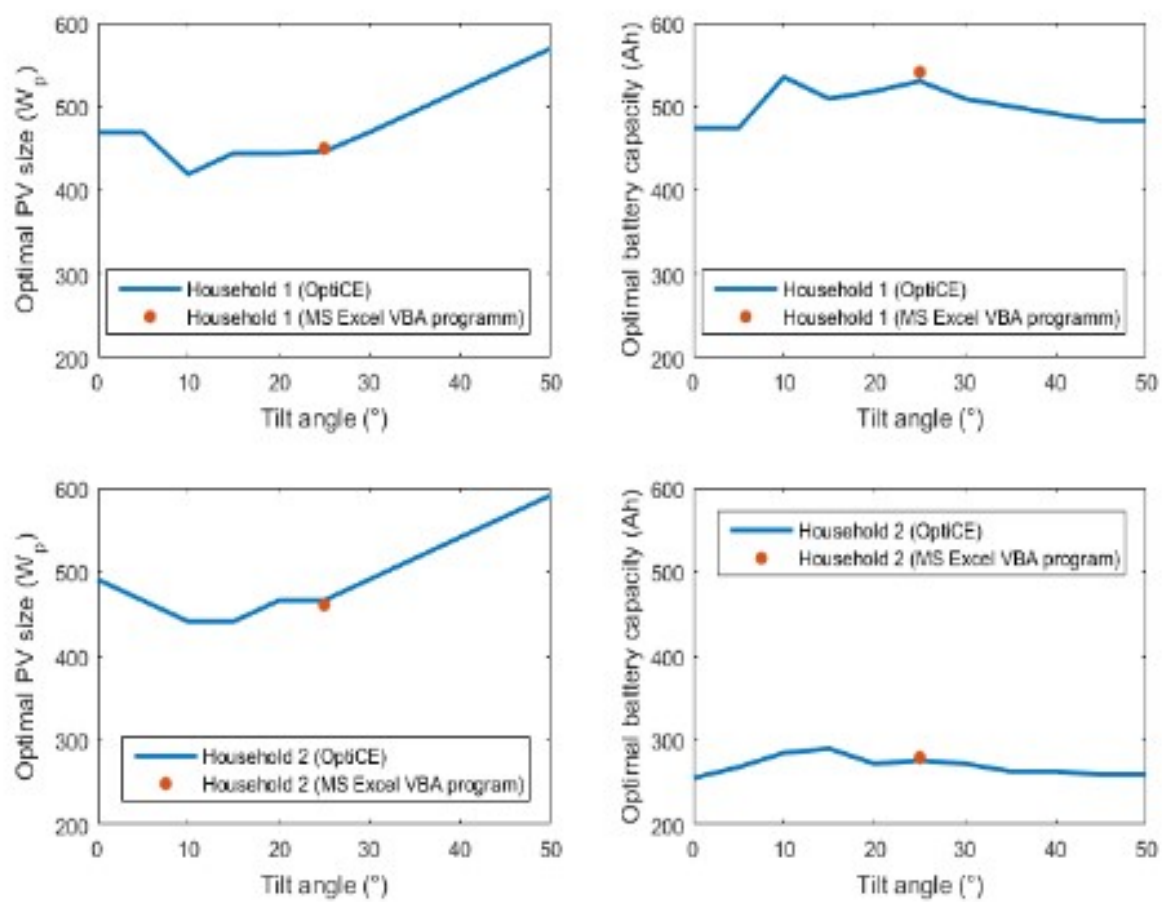

Fig. 11: Impact of the tilt angle on the PV (left) and battery (right) capacities for Households 1 and 2 .

\subsection{Model validation}

The simulation results of the developed MS Excel-VBA program were validated through comparison them with results obtained from PVsyst ${ }^{\circledR}$ and OptiCE using the same input data. The validation results are summarized in Table 5. The validation results are listed in terms of deviation between the results obtained with the developed MS Excel-VBA program and the results obtained by using PVsyst ${ }^{\circledR}$ and OptiCE.

Table 5: Validation results between the developed MS Excel-VBA program and both PVsyst ${ }^{\circledR}$ and OptiCE.

\begin{tabular}{|l|c|c|}
\hline Parameter & Deviation with PVsyst ${ }^{\circledR}$ (\%) & Deviation with OptiCE (\%) \\
\hline Average battery SOC (\%) & $1.57($ for H1) & 0.12 (for H1) \\
& $3.19($ for H2) & 0.34 (for H2) \\
\hline Annual power generation $(\mathrm{kWh})$ & $-1.61($ for H1) & - \\
\hline System reliability $(\%)$ & $0.35($ for H2) & -1.11 (for H1) \\
& - & -1.17 (for H2 \\
\hline & - & 0.12 (for H1) \\
Annual power generation $(\mathrm{kWh})$ & - & 0.33 (for H2) \\
\hline
\end{tabular}


The results from the MS Excel-VBA program show only minor deviations as compared to the commercial software PVsyst ${ }^{\circledR}$ and the open-source model OptiCE. All the deviations are below 4\%, confirming the accuracy of the developed MS Excel-VBA tool. The main reason for the deviation with PVsyst ${ }^{\circledR}$ is attributed to the system efficiencies. Indeed, PVsyst ${ }^{\circledR}$ takes into account several efficiencies and losses such as soiling (through an annual or monthly soiling loss factor) or mismatching losses that are not taken into account in the current version of the MS Excel-VBA tool developed for this study. In addition, different models for the PV array, charge controller and battery are used. Compared to the Matlab ${ }^{\circledR}$ based model, the developed tool shows almost the same results since most of the implemented equations are the same. The discrepancies can be explained by investigating the impact of the optimal PV system and battery capacity on the system reliability, depicted in Fig. 12. The figure refers to the H1 case study and has been obtained using OptiCE. The results achieved with the developed MS Excel-VBA program for REL values of $99.9 \%$ and $95.0 \%$ are also superimposed. 


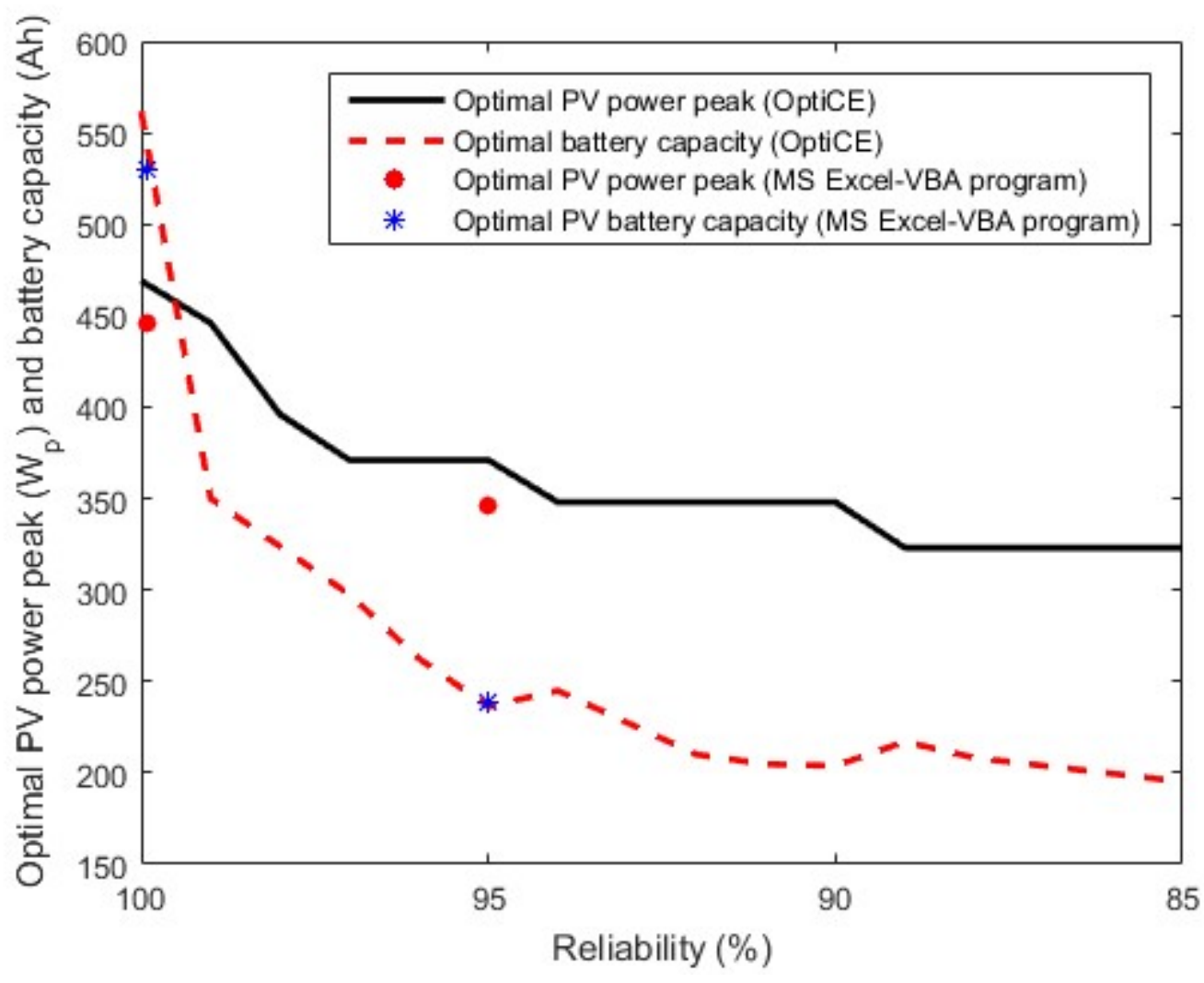

Fig. 12: Impact of the optimal PV system and battery capacity on the system reliability for Household 1.

In the reliability range between $100 \%$ and $95 \%$, the slopes of the two curves are relatively marked and small variation can cause high deviations in the results. In the reliability range $100 \%$ to $95 \%$, the optimal PV system capacity decreases by $20 \%$ while the optimal battery capacity decreases by $58 \%$. The results also suggest that, from a techno-economic viewpoint it is more economical to rely on back-up sources, such as candles, to deal with power shortages rather than designing a system with $100 \%$ reliability. It has to be noted that, the SHSs reliability is simultaneously guaranteed by the optimal PV power peak and by the optimal battery capacity. For instance, the SHSs reliability decreases from $96 \%$ down to $90 \%$ due to the decrease of the optimal battery capacity while the optimal PV capacity remains constant. The optimal combination of the PV power and battery capacities is due to the two 
pursued techno-economic objectives: maximizing the SHSs REL and at the same time minimizing the LCC. Good agreement is observed between the optimization values obtained with OptiCE and the developed MS Excel-VBA program. A typical result of double objective GA optimization carried out with OptiCE is depicted in Fig. 14. The graph shows the Pareto frontier between two competing objectives, maximizing REL and minimizing LCC. Each dot of the scatter plot represents an optimal point of the optimization process. The entire set of dots represents the mutual relationship between LCC and REL. The higher the REL is, and the higher the SHS LCC becomes. Each dot of the Pareto frontier corresponds to a set of optimal decisional variables such as azimuth angle, PV system, and battery capacities. The superimposed values obtained from the MS Excel-VBA program for the reliabilities $99.9 \%$ and $95.0 \%$ show good agreement with the results obtained with OptiCE.

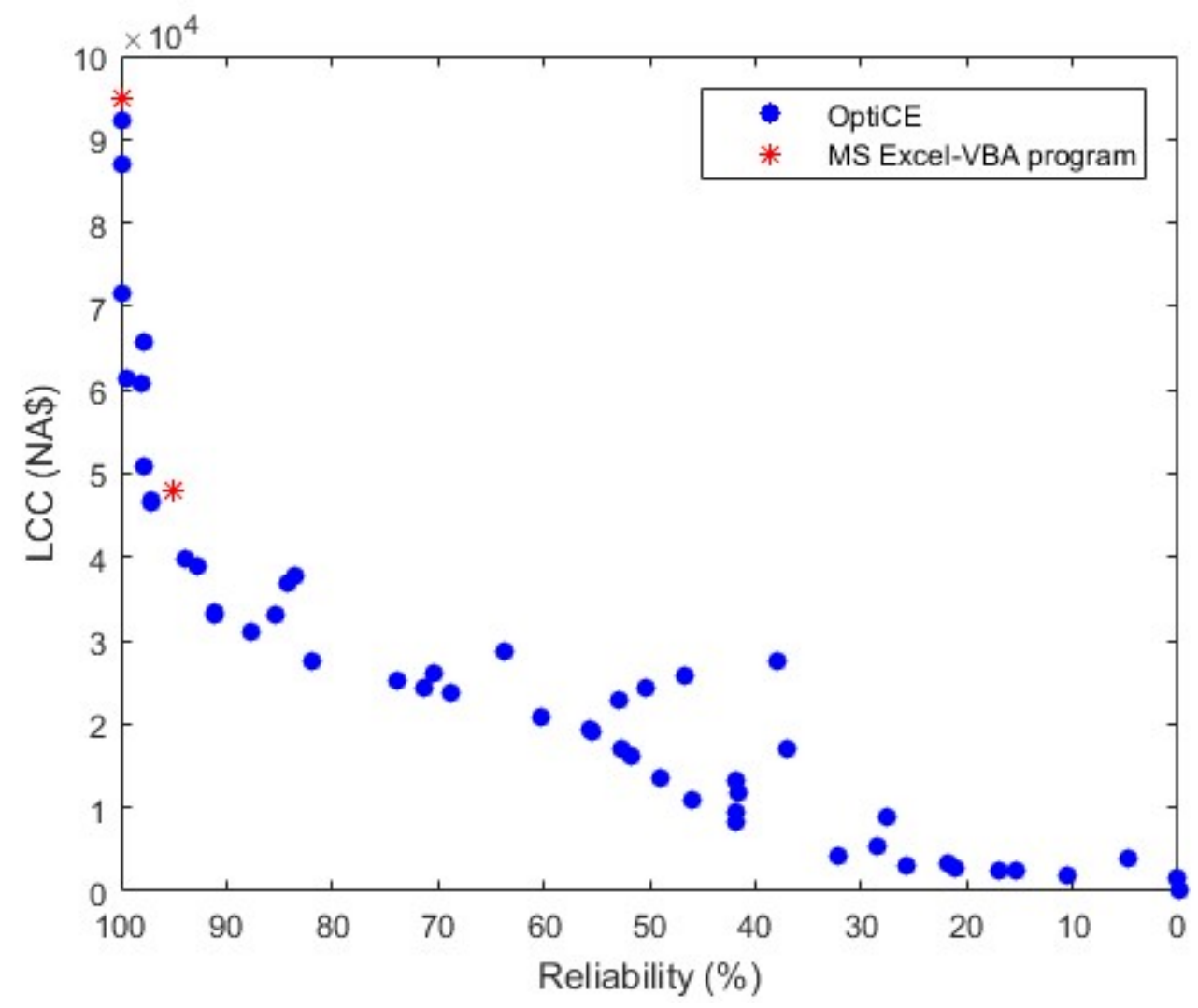

Fig. 14: Pareto frontier of the double objective optimization problem for Household 1. 


\section{Conclusions}

Solar home systems (SHSs) are a commonly used solution for achieving rural electrification targets. To decrease systems failures and improve the reputation of SHSs, it is of great importance to develop a tool that can be used by service providers to optimally design SHSs. The objective of this study was to develop an open-source optimization program written in MS Excel-VBA for designing SHSs components with special consideration of system reliability and life cycle costs. The developed tool has been validated with the data gathered in the field in Namibia.

The results show that the developed open-source program is a powerful tool for designing SHSs to determine the optimal combination and capacity of components based on a given load profile. The application of the tool to previously installed SHSs with the aim of highlighting the deficiencies of has been important for its validation. Moreover, the simulations and optimization results also show that the model is an excellent tool for optimal design of SHSs. The discrepancy of average battery SOC is below $4.0 \%$ whereas the discrepancy of the yearly power production is below $1 \%$ when compared with a commercial software and an open-source code for research activities. The optimization results show good agreement when compared with a Matlab® based model.

\section{Acknowledgments}

The authors would like to thank the KKS Future Energy Profile at Mälardalen University for the financial support. This work has also received funding from European Union's Horizon 2020 (No. 646529) and National High Technology Research and Development Program (863 program) of China (No. 2015AA050402). The authors Aksel Holmberg and Oscar Pettersson, gratefully thank Gustav Dahl scholarship at Mälardalen University for the financial support to conduct the survey in Namibia. One of the authors, Yang Zhang, acknowledges the financial support from China Scholarship Council (CSC). 


\section{References}

[1] Lighting Global, Bloomberg New Energy Finance, Global Off-Grid Lighting Association. Off-Grid Solar Market Trends. http://www.se4all.org/content/grid-energy-solutions-present-3billion-market-opportunity-investors-new-report-finds; 2016 [accessed 19.05.16]

[2] MDG Gap Task Force. Taking Stock of the Global Partnership for Development. http://www.un.org/millenniumgoals/pdf/MDG Gap 2015 E web.pdf; 2015 [accessed 19.05.16]

[3] World Bank. Addressing the Electricity Access Gap. http://siteresources.worldbank.org/EXTESC/Resources/Addressing_the_Electricity_Access_ Gap.pdf; 2010 [accessed 19.05.16]

[4] International Energy agency. Energy and Climate Change https://www.iea.org/publications/freepublications/publication/WEO2011 WEB.pdf; 2015 [accessed 19.05.16]

[5] International Energy Agency. World Energy Outlook 2015- Electricity Access Database. http://www.worldenergyoutlook.org/resources/energydevelopment/energyaccessdatabase; 2016 [accessed 19.05.16]

[6] D. von Oertzen. REEE-powering Namibia. Konrad-Adenauer-Stiftung. http://www.kas.de/wf/doc/kas_42216-1522-1-30.pdf?150810151915; 2015 [accessed 19.05.16]

[7] United Nations Development Programme. Off-grid Energisation Master Plan for Namibia.http://www.na.undp.org/content/dam/namibia/docs/enrgy\&enviro/undp na ergyenvi ro OGEMPReport 2007.pdf; 2007 [accessed 19.05.16]

[8] Ndhlukula K. Renewables for Growing Cities in Africa: A roadmap from 2012 to 2050- In the Context of Namibia. 
https://www.irena.org/DocumentDownloads/events/NaplesSeptember2012/Kuda_Ndhlukula. pdf; 2012 [accessed 19.05.16]

[9] Abdullah S, Markandya A.Rural electrification programmes in Kenya: Policy conclusions from a valuation study. Energy for Sustainable Development 16 (2012) 103-110

[10] Sandwell P, Chan NLA, Foster S, Nagpal D, Emmott CJM, Candelise C, Buckle SJ, Ekins-Daukes N, Gambhir A, Nelson J. Off-grid solar photovoltaic systems for rural electrification and emissions mitigation in India. Solar Energy Materials \& Solar Cells (in press)

[11] Center for Clean Air Policy (CCAP). Harnessing Solar Power for Rural ElectrificationNamibia. http://ccap.org/assets/CCAP-Booklet_Namibia.pdf; 2012 [accessed 19.05.16]

[12] Jain PK, Jain P, Dhafana P. Addressing Barriers to Off-Grid Rural Electrification in Africa: The Botswana and Namibia Experience. Journal of Energy and Power Engineering 8 (2014) 1351-1359

[13] Namibia Ministry of Mines and Energy. Code of Practice and Register of Products for Namibian Solar Energy Technologies. http://www.mme.gov.na/files/pdf/undp-reports/codeof-practice-products-for-namibian-sets.pdf; 2016 [accessed 19.05.16]

[14] International Renewable Energy Agency (IRENA).Accelerating off-grid renewable energy - IOREC 2014: key findings and recommendations; http://www.irena.org/DocumentDownloads/Publications/IRENA_2nd_IOREC_2015.pdf; 2015 [accessed 19.05.16]

[15] Sovacool BK, D’Agostino AL, Bambawale MJ. The socio-technical barriers to Solar Home Systems (SHS) in Papua New Guinea: "Choosing pigs, prostitutes, and poker chips over panels. Energy Policy 39 (2011) 1532-1542 
[16] Azimoh CL, Klintenberg P, Wallin F, Karlsson B. Illuminated but not electrified: An assessment of the impact of Solar. Applied Energy 155 (2015) 354-364

[17] Hangula A, Energy efficiency specialist at Namibia Energy Institute, 2016. Personal communication with A. Holmberg

[18] Kulworawanichpong T, Mwambeleko JJ. Design and costing of a stand-alone solar photovoltaic system for a Tanzanian rural household. Sustainable Energy Technologies and Assessments 12 (2015) 53-59

[19] Azimoh CL, Wallin F, Klintenberg P, Karlsson B. An assessment of unforeseen losses resulting from inappropriate use of solar home systems in South Africa. Applied Energy 136 (2014) 336-346

[20] Ministry of Mines and Energy, Renewable Energy Technology Financing, http://www.mme.gov.na/energy/srf/; 2016 [accessed 19.05.16]

[21] Suresh Kumar U, Manoharan PS. Economic analysis of hybrid power systems (PV/diesel) in different climatic zones of Tamil Nadu. Energy Conversion and Management 80 (2014) 469-476

[22] Kusakana K. Optimal scheduling for distributed hybrid system with pumped hydro storage. Energy Conversion and Management 111 (2016) 253-260

[23] Azimoh CL, Klintenberg P, Wallin F, Karlsson B, Mbohwa C. Electricity for development: Mini-grid solution for rural electrification in South Africa. Energy Conversion and Management 110 (2016) 268-277

[24] Kanyarusoke KE, Gryzagoridis J, Oliver G. Re-mapping sub-Sahara Africa for equipment selection to photo electrify energy poor homes. Applied Energy 175 (2016) 240250 
[25] Zubi G, Dufo-López R, Pardo N, Pasaoglu G.Concept development and techno-economic assessment for a solar home system using lithium-ion battery for developing regions to provide electricity for lighting and electronic devices. Energy Conversion and Management 122 (2016) 439-448

[26] Campana PE, Li H, Zhang J Zhang R, Liu J, Yan J. Economic optimization of photovoltaic water pumping systems for irrigation. Energy Conversion and Management 95 (2015) 32-41

[27] OptiCE, www.optice.net; 2016 [accessed 19.05.16]

[28] Zhang Y, Lundblad A, Campana PE, Yan J. Comparative study of employing battery and hydrogen storages to increase photovoltaic self-sufficiency in a residential building of Sweden. Renewable Energy Integration with Mini/Microgrid REM2016, April 19-21, 2016, Maldives

[29] Zhang Y, Lundblad A, Campana PE, Yan J. Study on employing battery storages to increase photovoltaic self-sufficiency in a residential building of Sweden. Energy Procedia 88 (2016) $455-461$

[30] Campana PE, Quan SJ, Robbio FI, Lundblad A, Zhang Y, Ma T, Yan J.Spatial optimization of residential urban district - Energy and water perspectives. Energy Procedia 88 ( 2016$) 38-43$

[31] Nookuea W, Campana PE, Tan Y, Yan J. Hybrid power system for sustainable shrimp farm. Renewable Energy Integration with Mini/Microgrid REM2016, April 19-21, 2016, Maldives 
[32] Nookuea W, Campana PE, Yan J. Evaluation of solar PV and wind alternatives for selfrenewable energy supply: case study of shrimp cultivation. Energy Procedia 88 ( 2016 ) 462 469].

[33] Duffie JA, Beckman VA. Solar engineering of thermal processes. 3rd ed. Wiley; 2006

[34] Kaabeche A, Belhamel M, Ibtiouen .R. Techno-economic valuation and optimization of integrated photovoltaic/wind energy conversion system. Solar Energy 85 (2011) 2407-2420

[35] The Drivers of the Levelized Cost of Electricity for Utility-Scale Photovoltaics, https://us.sunpower.com/sites/sunpower/files/media-library/white-papers/wp-levelized-costdrivers-electricity-utility-scale-photovoltaics.pdf; 2008 [accessed 07.07.16]

[36] SolveXL, http://www.solvexl.com/; 2016 [accessed 16.08.16]

[37] Lynn PA. Electricity from sunlight. 1st ed. UK: Wiley; 2010.

[38] SolarGIS, http://solargis.info/; 2016 [accessed 07.07.16]

[39] Electricity Control Board, http://www.ecb.org.na/; 2016 [accessed 07.07.16]

[40] Campana PE, Li H, Yan J. Techno-economic feasibility of the irrigation system for the grassland and farmland conservation in China: photovoltaic vs. wind power water pumping. Energy Conversion and Management 103 (2015) 311-320

[41] Meteonorm, http://www.meteonorm.com/en/; 2016 [accessed 28.08.16] 